Portland State University

PDXScholar

$5-21-2020$

\title{
Genetic Diversity Correlates with Morphological Diversity Among Populations of Achyrachaena mollis
}

Rachel S. Bice

Portland State University

Follow this and additional works at: https://pdxscholar.library.pdx.edu/honorstheses

Part of the Plant Biology Commons

Let us know how access to this document benefits you.

\section{Recommended Citation}

Bice, Rachel S., "Genetic Diversity Correlates with Morphological Diversity Among Populations of Achyrachaena mollis" (2020). University Honors Theses. Paper 871.

https://doi.org/10.15760/honors.892

This Thesis is brought to you for free and open access. It has been accepted for inclusion in University Honors Theses by an authorized administrator of PDXScholar. Please contact us if we can make this document more accessible: pdxscholar@pdx.edu. 
Genetic Diversity Correlates with Morphological Diversity Among Populations of Achyrachaena mollis

by

Rachel Bice

An undergraduate honors thesis submitted in partial fulfillment of the requirements of the degree of

Bachelor of Science

in

University Honors

and

Biology

Thesis Advisor

Mitchell Cruzan, Ph.D.

Portland State University

2020 


\section{ABSTRACT}

Biodiversity is important for ecosystem health and sustainability, especially in the current, rapidly changing climate. Understanding the underlying causes behind morphological variation will allow for more accurate predictions about how a population will respond to climate change, and potentially yield better natural resource management strategies. Achyrachaena mollis is an annual, self-fertilizing, a range-limited, endemic species found in Northern California and Southern Oregon. This species depends primarily on wind seed dispersal for gene flow, making it a good study species in seed dispersal experiments. Additionally, $A$. mollis is more readily influenced by changes in its environment than a perennial due to its annual nature. In this study, I analyzed morphological variation among eleven populations of $A$. mollis seeds against variation in both chloroplast DNA (cpDNA) haplotypes and environmental factors. Morphological seed traits varied significantly between populations $(P<0.01, N=1,181)$, providing material for selection and evolution. Morphological variation was found to correlate with cpDNA variation $(P<0.10)$. This indicates that morphological diversity is likely the product of long-term cycles of mutation and evolution. Additionally, morphological variation correlated with soil-clay content $(P<0.05)$, likely due to availability of water and nutrients.

\section{KEYWORDS}

Achyrachaena mollis, seed dispersal, morphological variation, phenotypic plasticity, climate change, anemochory

\section{INTRODUCTION}

For centuries, humans have pondered the source of phenotypic diversity among organisms. Diversity is a key component of healthy ecological systems at all levels of biological organization. At the community level, species interact to exchange resources. Within- and among-populations, diversity provides material for selection and adaptation. Diversity is evident in populations both large and small, even when populations share most of their genome. This begs the question: is observable diversity due to genetic variation or phenotypic plasticity? Frequently, diversity is a combination of both genetic and environmental factors.

Morphological diversity within- and among-populations could be explained by enduring cycles of mutation and evolution, leading to variation in an individual's genotype. Moreover, morphological diversity could be the product of a more proximate response to a local environment in the form of phenotypic plasticity. Phenotypic plasticity is caused by varying gene expression, making it a more elastic response to one's environment. Understanding the underlying causes behind morphological variation will allow for more accurate predictions 
about how a population will respond to climate change, and potentially yield better natural resource management strategies (Cochrane et al., 2015).

Furthering our understanding of seed dispersal is also important due to increasing pressures of climate change on species' habitat range and dispersal. To effectively predict how plant populations will react to rising temperatures and habitat loss, seed dispersal must be studied (Cochrane et al., 2015; Johnson et al., 2019). In response to climate change, plant population distributions are altered through range expansion and novel colonization. However, human modification of landscapes and fragmentation can disrupt these processes. This could present an advantage for species that utilize long-distance dispersal, as fragmentation can impede short-distance dispersal processes by creating low-quality habitat and physical barriers. Longdistance dispersal is especially important in the current climate due to its role in maintaining gene flow across populations, colonization of novel locations, and range expansion (Bacles et al., 2006). Maintaining gene flow across populations enhances diversity within populations and reduces inbreeding. Long-distance dispersal may also lead to population establishment and range expansion (Chybicki et al., 2018), which are vital tools in the fight against habitat loss and fragmentation.

Wind dispersal (anemochory) is one dispersal syndrome associated with long-distance seed movement. In most wind dispersal experiments, traits of the parent plant have been the primary focus; morphological traits of individual seeds are not observed closely. Some experiments have considered the height of the parent plant from which seeds disperse (Johnson et al., 2019) or the mass of seeds (Millberg et al., 2009; McWilliams et al., 2020) with regards to seed dispersal, while others ignore morphological characteristics altogether. Greater morphological diversity within- and among-populations allows for greater adaptive advantage in response to climate change and other selective pressures. Morphological traits may be affected by genetic or environmental characteristics acting upon an individual or a population. Morphological seed traits such as pappus diameter, pappus-achene angle, and wing width are likely to affect a seed's potential for dispersal, as these traits will facilitate wind dispersal. The drag and vortex created by a seed's pappus will affect its flight ability. These characteristics are influenced by its size, shape, and porosity (Cummins et al., 2018). However, there are many variables that will affect seed dispersal ability. At the local scale, these factors include seedrelease height (Nathan et al., 2002; Johnson et al., 2019), abscission force (Treep et al., 2018), seed morphology (Nathan et al., 2002; Andersen, 1993), and small-scale turbulence (Nathan et al., 2002). At the regional scale, dispersal is influenced by landscape features (Grasty et al., 2020), meteorological events, and regional wind patterns (Treep et al., 2018).

Achyrachaena mollis is a range-limited, endemic species found primarily in Northern California. Due to a reduced corolla and frequent autogamous self-reproduction strategy, $A$. mollis experiences limited pollinator activity, and gene flow is primarily dependent on seed dispersal 
(Jepson, 1975; Munz et al., 1968). Information about the seed dispersal strategies of $A$. mollis is lacking, probably due to its limited distribution. $A$. mollis is most likely wind dispersed, as it has a large, robust pappus, seen in many other wind-dispersed species (e.g. many members of Asteraceae family). A. mollis is an adequate study species in research regarding climate change, as it is an annual herb. Annual herbs have shorter generation times, expediting evolution and making them more readily influenced by changes in the environment than perennials.

In this study, I used a collection of morphological measurements in conjunction with chloroplast haplotype diversity and various environmental characters to explore patterns between morphological, genetic, and environmental variation. My aim is to determine whether variation in among-population seed morphology and subsequently, dispersal, is influenced by genetic or environmental variables. If morphological variation among populations is more heavily correlated with chloroplast haplotype frequencies, then chloroplast genotypic variation is most likely the driver behind morphological diversity of seeds. If morphological variation among seed populations is better predicted by spatial heterogeneity and environmental variables, then phenotypic plasticity would be a more likely predictor of phenotypic diversity of seeds. However, I expect to see a combination of these two processes influencing seed morphology variation.

\section{METHODS}

\section{Data Collection}

Seeds of Achyrachaena mollis were collected from areas surrounding Medford, Oregon, including the unique geological feature; the Table Rocks, which are mesas in the Rogue River Valley. Seeds were collected from sixteen separate locations of $A$. mollis at varying distances across a nine-hundred square-kilometer study range, each representing independent populations (Fig. 1). Ten plants from each of sixteen populations were selected, and ten to twelve seeds were collected from each plant.

Seed morphological features were imaged and measured, including: pappus-achene angle (degrees), long wing length $(\mathrm{cm})$, short wing length $(\mathrm{cm})$, long wing width $(\mathrm{cm})$, short wing width $(\mathrm{cm})$, pappus diameter $(\mathrm{cm})$, and achene length $(\mathrm{cm}$; Fig. 2). These seeds were placed under a microscope and photographed at 7.1 total magnification using the software Image Pro Plus by Media Cybernetics. Measurements were taken from two directions: lateral and posterior (Fig. 2). A total of 1,614 seeds were measured, with approximately $75 \%$ of seeds measured by one researcher, and $25 \%$ measured by another. Seed mass (mg) was determined by weighing all seeds from one individual and then dividing by the number of seeds collected. A subset of seed populations from eleven populations was used in the following analyses ( $n=$ 1,181). 
Chloroplast DNA (cpDNA) was utilized due to its highly conserved nature, allowing the inheritance of mutations to be tracked. Additionally, cpDNA is maternally inherited, so any gene flow seen represents seed dispersal independent of pollen movement. Chloroplast DNA was isolated and quantified using procedure described in Grasty et al. (2020). Population-level cpDNA was pooled in an equimolar fashion and sequenced, in addition to single-sample libraries. Samples were sequenced by Oregon Health and Science University (OHSU), Massively Parallel Sequencing Shared Resource (MPSSR) in Portland, Oregon, USA.

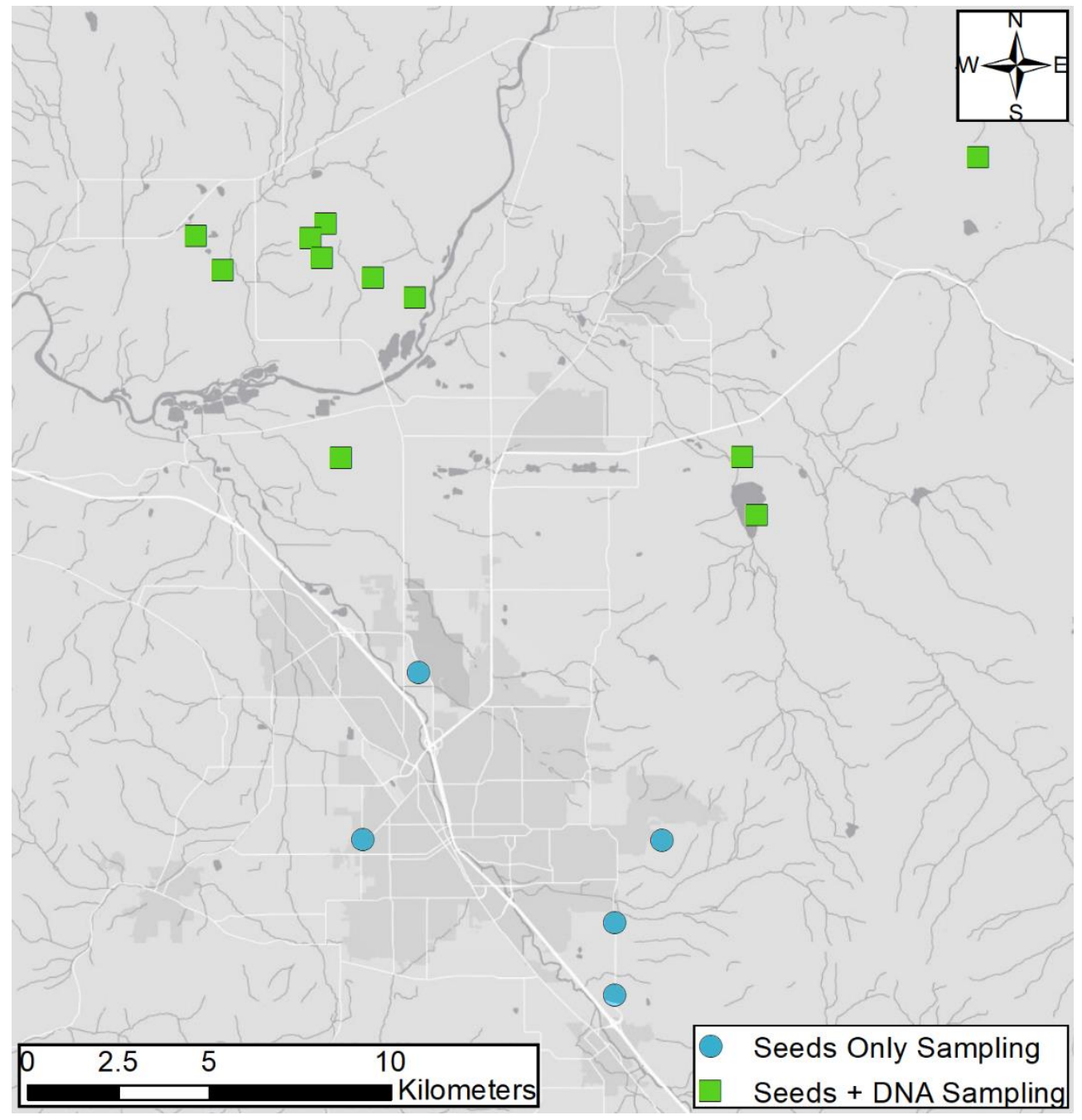

Figure 1: This map depicts populations sampled in and around Medford in southern Oregon. Blue circle markers delineate sites included in the seed morphological analysis, and green square markers represent populations where both seeds and leaf tissue for cpDNA extraction were collected. 


\section{Quantifying Morphological Variation}

The dispersion of each morphological trait was displayed for each population using box-andwhisker plots. Irregular measurements were identified as data collection errors and removed (four seeds were removed in total). Morphological variation data was aggregated by averaging the morphological traits of one individual together, then using these data to find overall population averages. Significant morphological variation between populations was identified using the ANOVA function from the R stats package v3.6.3.

A Principle Components Analysis (PCA) was used to measure variation of all seed traits among populations. Variation was described using the distance to centroid of the graph. The vector length was found by applying the Pythagorean Theorem to the centroid positions of each population $\left(\sqrt{x^{2}+y^{2}}\right)$. This distance represents the overall variation of morphological traits; as the distance increases, the morphological differentiation increases.
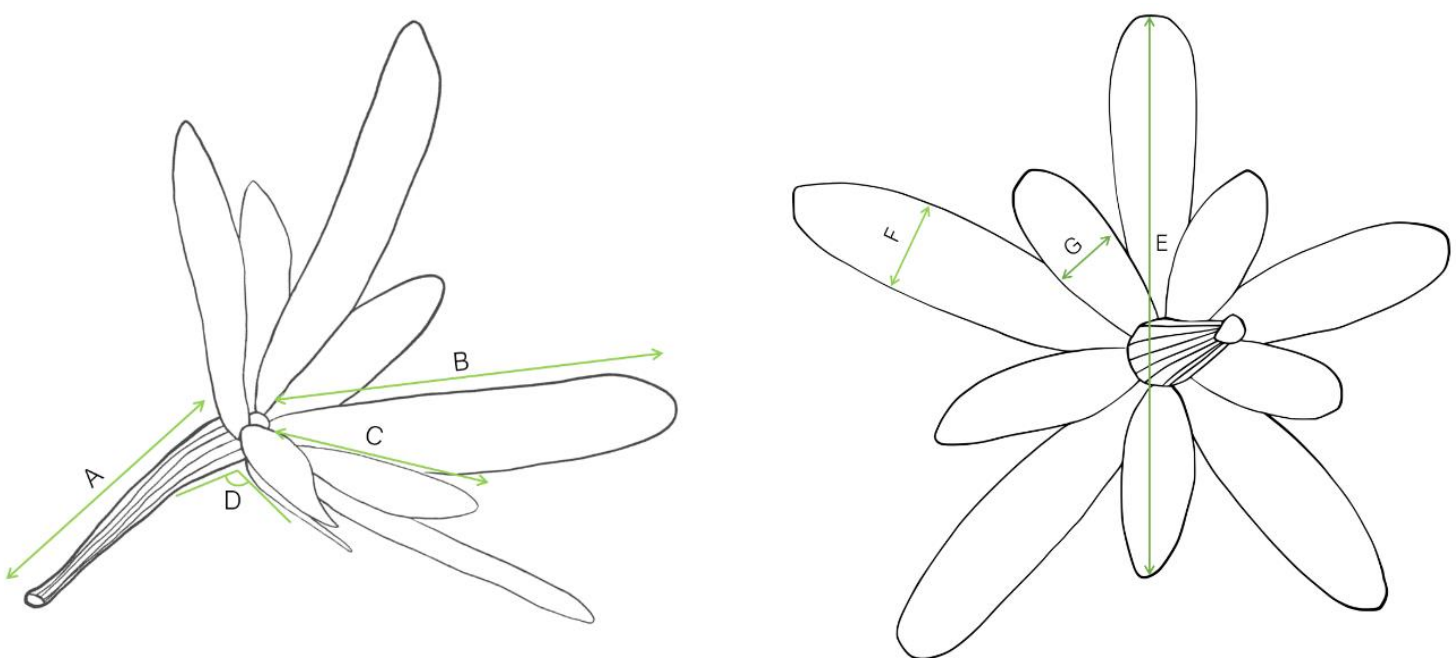

Figure 2: Diagrams of seed measurements, where $A$ is achene length, $B$ is long wing length, $C$ is short with length, $D$ is pappus-achene angle, $E$ is pappus diameter, $G$ is short wing width, and $F$ is long wing width.

\section{Genetic Diversity Analysis}

Population diversity among populations was quantified using haplotype frequencies obtained from chloroplast DNA. Single nucleotide polymorphisms (SNPs) were analyzed by the program CallHap to identify unique haplotypes (Kohrn et al., 2017). Genetic differentiation was measured using haplotype diversity in terms of expected heterozygosity (Hs) using the adegenet R package v2.1.2 (Jombart, 2008) for each of eleven populations. Correlation between Hs values and morphological variation was identified using a Generalized Least Squares (GLS) model from the $n / m e$ R package v3.1-144 (Pinheiro, 2017). 


\section{Environmental Diversity Analysis}

Environmental factors were evaluated using ArcGIS v10.7 to examine spatial heterogeneity that may influence phenotypic plasticity of $A$. mollis. Environmental factors included soil moisture, clay content of soil, elevation, average annual precipitation, tree canopy, and average annual temperature. Soil data were supplemented by Natural Resources Conservation Service (NRCS) public databases. Elevation data were obtained from the Oregon Geospatial Enterprise Office. Tree canopy data were obtained from the National Land Cover Database (NLCD) United States Forest Service (USFS) Tree Canopy Change (CONUS). Precipitation and temperature data were obtained from the Prism Climate Group (OSU). GLS models were used to determine correlations between environmental variables and morphological variation. Univariate and bivariate combinations were used for analysis of environmental variables.

Habitat suitability was evaluated using Maxent (Phillips, 2006). Population location data were supplemented by the Consortium of Pacific Northwest Herbaria. Variables included in the Maxent model were clay composition, average annual precipitation, average annual temperature, and percent soil moisture. Several different models were tested for habitat suitability, including Linear, Linear-Quadratic, Linear-Hinge, Quadratic Hinge, and LinearQuadratic models, which are recommended for small sample sizes. Ultimately, a Hinge model was determined as the best fit using the area under the curve (AUC) metric and was compared to morphological variation using a GLS model.

\section{RESULTS}

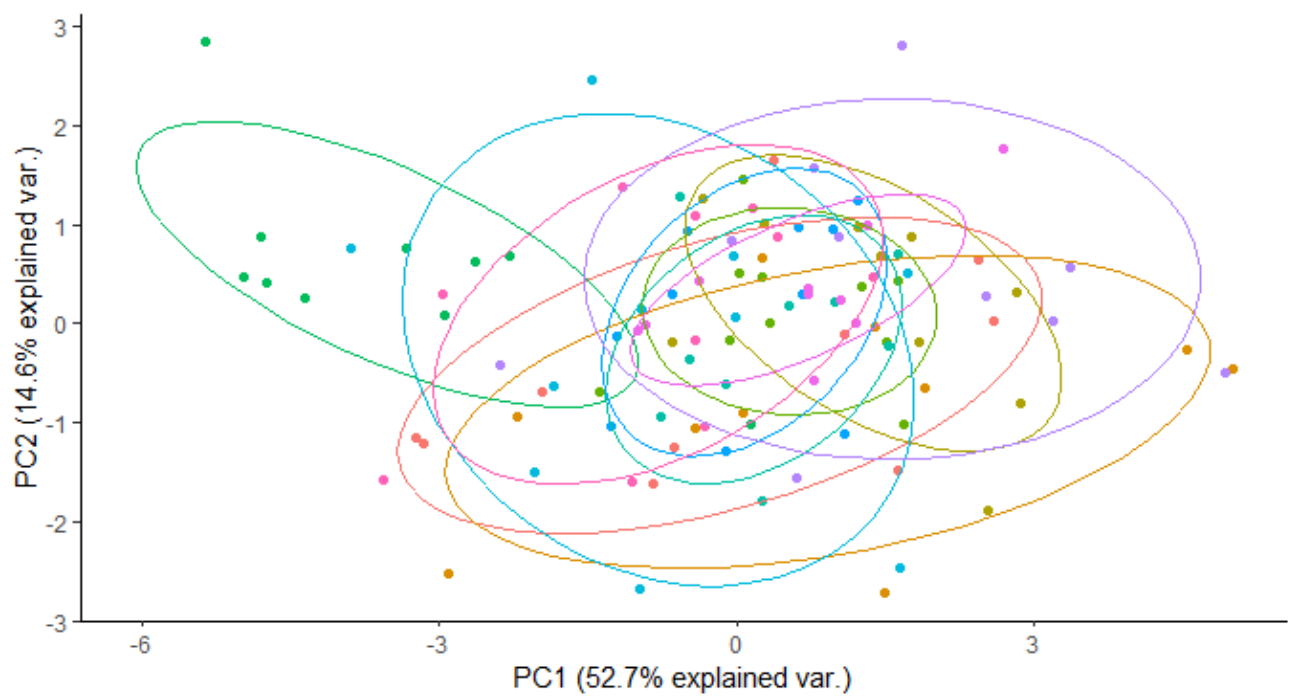

Figure 3: PCA of population-level seed morphology shows variation among populations. Each group color denotes a unique population. 
Morphological traits showed significant variation among populations (Table 1; Fig. 3).

Comparisons of each individual morphological trait across all populations in an ANOVA were significant ( $p$-value $<0.01, \mathrm{df}=14, \mathrm{n}=1,181$ ). Genetic diversity $(\mathrm{Hs}$ ) and morphological variation were slightly correlated $(p=0.067)$ during GLS analysis. Morphological variation correlated with soil clay content ( $p=0.040$; Table 2$)$ when analyzed with GLS. However, all other environmental variables showed no correlation with morphological variation. Habitat suitability (Maxent) analysis with GLS also showed no correlation with morphological variation $(p=0.24)$.

Table 1: Population averages of all eight morphological traits. SWL: short wing length (cm); LWL: long wing length (cm); AL: achene length (cm); PAA: pappus-achene angle (degrees); PD: pappus diameter (cm); LWW: long wing width (cm); SWW: short wing width (cm).

\begin{tabular}{|l|l|l|l|l|l|l|l|l|}
\hline Population & $\begin{array}{l}\text { SWL } \\
(\mathbf{c m})\end{array}$ & $\begin{array}{l}\text { LWL } \\
(\mathbf{c m})\end{array}$ & $\begin{array}{l}\text { AL } \\
(\mathbf{c m})\end{array}$ & $\begin{array}{l}\text { PAA } \\
\text { (degrees) }\end{array}$ & $\begin{array}{l}\text { PD } \\
(\mathbf{c m})\end{array}$ & $\begin{array}{l}\text { LWW } \\
(\mathbf{c m})\end{array}$ & $\begin{array}{l}\text { SWW } \\
(\mathbf{c m})\end{array}$ & $\begin{array}{l}\text { Mass } \\
(\mathbf{m g})\end{array}$ \\
\cline { 2 - 9 } BLM & 0.467 & 0.859 & 0.682 & 127.70 & 1.33 & 0.200 & 0.143 & 0.556 \\
\hline DEN & 0.428 & 0.839 & 0.646 & 126.61 & 1.27 & 0.190 & 0.133 & 0.480 \\
\hline DCR & 0.430 & 0.899 & 0.699 & 128.29 & 1.32 & 0.185 & 0.136 & 0.452 \\
\hline DR & 0.437 & 0.806 & 0.669 & 128.37 & 1.26 & 0.186 & 0.133 & 0.542 \\
\hline LTR1 & 0.508 & 0.948 & 0.735 & 113.87 & 1.49 & 0.188 & 0.140 & 0.942 \\
\hline UTR2 & 0.468 & 0.920 & 0.688 & 118.69 & 1.42 & 0.191 & 0.138 & 0.595 \\
\hline UR3 & 0.486 & 0.943 & 0.730 & 129.35 & 1.38 & 0.193 & 0.155 & 0.529 \\
\hline UW2 & 0.438 & 0.969 & 0.685 & 124.46 & 1.54 & 0.207 & 0.151 & 0.531 \\
\hline WHS & 0.494 & 0.870 & 0.650 & 126.11 & 1.43 & 0.198 & 0.148 & 0.577 \\
\hline
\end{tabular}


Table 2: P-values obtained from univariate and bivariate GLS analysis. Significant P-values are indicated in bold.

\begin{tabular}{|l|l|}
\hline Factor & P-value \\
\hline Soil Moisture & 0.1345 \\
\hline Soil Clay Content & $\mathbf{0 . 0 4 0 4}$ \\
\hline Elevation & 0.3209 \\
\hline Precipitation & 0.8780 \\
\hline Canopy & 0.7607 \\
\hline Temperature & 0.4132 \\
\hline Habitat Suitability & 0.2389 \\
\hline Genetic Diversity (Hs) & 0.0674 \\
\hline Soil Salinity + Clay Content & 0.5644 \\
\hline Soil Salinity + Elevation & 0.6795 \\
\hline Soil Salinity + Precipitation & 0.8814 \\
\hline Soil Salinity + Tree Canopy & 0.9442 \\
\hline Soil Salinity + Temperature & 0.8135 \\
\hline Clay Content + Elevation & 0.4344 \\
\hline Clay Content + Precipitation & 0.4237 \\
\hline Clay Content + Tree Canopy & 0.7222 \\
\hline Clay Content + Temperature & 0.4927 \\
\hline Elevation + Precipitation & 0.7831 \\
\hline Elevation + Tree Canopy & 0.5721 \\
\hline Elevation + Temperature & 0.4237 \\
\hline Precipitation + Canopy & 0.9166 \\
\hline Precipitation + Temperature & 0.6296 \\
\hline Canopy + Temperature & 0.5721 \\
\hline
\end{tabular}

\section{DISCUSSION}

Eight morphological seed traits were measured from eleven populations of Achyrachaena mollis across a nine-hundred square-kilometer range in Southern Oregon. Variation in these traits was compared to variation in cpDNA haplotype frequencies and environmental features to determine the underlying causes for morphological diversity.

\section{Morphological variation, seed dispersal, and climate change}

Achyrachaena mollis displayed significant seed morphological diversity among eleven populations (Table 1; Fig. 1). This is especially valuable in our rapidly changing climate, which threatens the biodiversity and sustainability of many ecosystems. Biodiversity is crucial to ecosystem health and is threatened by human developments causing global warming, fragmentation of habitat, and habitat loss. 
Trait variation among populations provides an adaptive advantage against changing environments (Johnson et al., 2018). Phenotypic traits of seeds affect their ability for seed dispersal (Nathan et al., 2002; Andersen, 1993), indicating that different populations will vary in their ability to successfully colonize new environments, expand their ranges, and maintain gene flow among populations. Morphological seed traits have been observed to pose fitness tradeoffs. For example: larger seeds are associated with greater food storage, but lighter seeds are more buoyant easily dispersed via wind (McWilliams et al., 2020). If variation in mass and other morphological traits among populations are determined by local adaptation, it will provide material for selection and adaptation in changing environments.

\section{Genetic variation and phenotypic plasticity}

Morphological variation was marginally significant when correlated with genetic variation among populations (Table 2), indicating that morphological variation is may be due to enduring cycles of selection and evolution in contrast to a more short-term, plastic response to the environment. Morphological variation did not show significant correlation with any environmental variables except for soil-clay content (Table 2). This lack of correlation indicates that $A$. mollis has a limited plastic response to its environment: a potentially disadvantageous quality in the face of a rapidly changing climate. However, A. mollis also demonstrates short generation times due to its annual nature, providing a mechanism for rapid adaptation to a contemporary change in the environment. In contrast, perennials have longer generation times causing slower rates of mutation and evolution.

Although morphological seed traits of $A$. mollis did not show correlation with most environmental variables, additional components could be considered, such as habitat fragmentation (due to roads or rivers) and local geography. Additionally, seed germination timing could be studied in the context of phenotypic plasticity, as it has been observed to correlate with environmental variation (McWilliams et al., 1967).

\section{Morphological variation and content of clay in soil}

Morphological variation showed a correlation with variation in soil-clay content (Table 2). Soilclay content has been observed to affect nitrogen concentration within soil (Castellano et al., 2009). Nitrogen plays an important role in production of carbohydrates during photosynthesis, providing energy for the plant. Additionally, nitrogen is important for synthesis of proteins involved in plant structure and many other cell processes (Parnes, 2013). This nutrient provides a potential connection between morphological variation of seeds and content of clay in soil.

Soil-clay content could also be responsible for impeding germination of seeds and increasing water availability to roots. Increasing water availability could lead to larger, healthier seeds. However, the natural stiffness of clay could pose challenges for infiltration of seeds into soil and seed germination. 


\section{Conclusions}

Morphological seed traits among populations of $A$. mollis vary significantly, providing material for selection and adaptation to a rapidly changing climate. Morphological seed trait variation among populations correlates with variation in chloroplast haplotype frequencies, indicating a morphological variation is likely due to enduring cycles of selection and evolution.

Morphological seed trait variation among populations also correlates with soil-clay content, likely due to availability of water and nutrients in combination with germination ability. Overall, information about the underlying causes of diversity among populations of $A$. mollis could be utilized for natural resource management and habitat conservation.

\section{ACNKOWLEDGEMENTS}

Elizabeth Scott played a major role in the production of this study. Lizzi guided me through analyses in $\mathrm{R}$, made all the figures, and edited draft after draft. Thank you Lizzi for your unwavering support and patience!

Thanks to Mitchell Cruzan for allowing me to join his lab, despite not having a place for me! I am incredibly grateful for the opportunity to work with you.

Thank you to those above and all the other members of the lab: Jaime Schwoch, Nicolas Diaz, Karla Berg, Dano Holt, and Amanda Burrell for providing much-needed feedback and discussion.

\section{REFERENCES}

Andersen, M. C. (1993). Diaspore morphology and seed dispersal in several wind-dispersed Asteraceae. American Journal of Botany, 80(5), 487-492.

Bacles, C. F., Lowe, A. J., \& Ennos, R. A. (2006). Effective seed dispersal across a fragmented landscape. Science, 311(5761), 628-628.

Bonte, D., Hovestadt, T., \& Poethke, H. J. (2010). Evolution of dispersal polymorphism and local adaptation of dispersal distance in spatially structured landscapes. Oikos, 119(3), 560-566.

Castellano, M. J., \& Kaye, J. P. (2009). Global within-site variance in soil solution nitrogen and hydraulic conductivity are correlated with clay content. Ecosystems, 12(8), 1343-1351.

Chybicki, I. J., \& Oleksa, A. (2018). Seed and pollen gene dispersal in Taxus baccata, a dioecious conifer in the face of strong population fragmentation. Annals of Botany, 122(3), 409-421. 
Cochrane, A., Yates, C. J., Hoyle, G. L., \& Nicotra, A. B. (2015). Will among-population variation in seed traits improve the chance of species persistence under climate change? Global Ecology and Biogeography, 24(1), 12-24.

Cummins, C., Seale, M., Macente, A., Certini, D., Mastropaolo, E., Viola, I. M., \& Nakayama, N. (2018). A separated vortex ring underlies the flight of the dandelion. Nature, 562(7727), 414-418.

Grasty, M. R., Thompson, P. G., Hendrickson, E. C., Pheil, A. E., \& Cruzan, M. B. (2020). Finescale habitat heterogeneity and vole runways influence seed dispersal in Plagiobothrys nothofulvus. American Journal of Botany, 107(July 2019), 413-422.

Jepson, L. Willis (1975). A Manual of the Flowering Plants of California. London, England: University of California Press (1104).

Johnson, J. S., Cantrell, R. S., Cosner, C., Hartig, F., Hastings, A., Rogers, H. S., Pufal, G. (2019). Rapid changes in seed dispersal traits may modify plant responses to global change. $A o B$ PLANTS, 11(3), 1-20.

Jombart, T. (2008). adegenet: an R package for the multivariate analysis of genetic markers. Bioinformatics, 24(11), 1403-1405.

Kaliontzopoulou, A., Pinho, C., \& Martínez-freiría, F. (2018). Where does diversity come from? Linking geographical patterns of morphological, genetic, and environmental variation in wall lizards. BMC Evolutionary Biology 18:124, 1-13.

Kohrn, B. F., Persinger, J. M., \& Cruzan, M. B. (2017). An efficient pipeline to generate data for studies in plastid population genomics and phylogeography. Applications in plant sciences, 5(11).

Milberg, P., Perez-fernandez, M. A., \& Lamont, B. B. (2009). Seedling Growth Response to Added Nutrients Depends on Seed Size in Three Woody Genera. British Ecological Society.

Munz, A. Philip, Keck, D. David (1968). A California Flora. Berkley/L.A., California: University of California Press (1107).

Nathan, R., Katul, G. G., Horn, H. S., Thomas, S. M., Oren, R., Avissar, R., Pacala, S. W., \& Levin, S. A. (2002). Mechanisms of long-distance dispersal of seeds by wind. Nature, 418(6896), 409-413. 
Parnes, Robert (2013). Nitrogen. Northeast Organic Farming Association, Soil, Ch. 10.

Phillips, S., Anderson, R., Schapire, R. (2006). Maximum entropy modeling of species geographic distributions. Ecological Modelling, 190:231-259, 2006.

Pinheiro, J., Bates, D., DebRoy, S., Sarkar, D., Heisterkamp, S., Van Willigen, B., \& Maintainer, R. (2017). Package 'nlme'. Linear and nonlinear mixed effects models, version, 3.

Treep, J., de Jager, M., Kuiper, L. S., Duman, T., Katul, G. G., \& Soons, M. B. (2018). Costs and benefits of non-random seed release for long-distance dispersal in wind-dispersed plant species. Oikos, 127(9), 1330-1343. 